Supplement of Clim. Past, 12, 1663-1679, 2016

http://www.clim-past.net/12/1663/2016/

doi:10.5194/cp-12-1663-2016-supplement

(C) Author(s) 2016. CC Attribution 3.0 License.

(c) (i)

Supplement of

\title{
Hosed vs. unhosed: interruptions of the Atlantic Meridional Overturning Circulation in a global coupled model, with and without freshwater forcing
}

Nicolas Brown and Eric D. Galbraith

Correspondence to: Eric D. Galbraith (eric.d.galbraith@gmail.com)

The copyright of individual parts of the supplement might differ from the CC-BY 3.0 licence. 

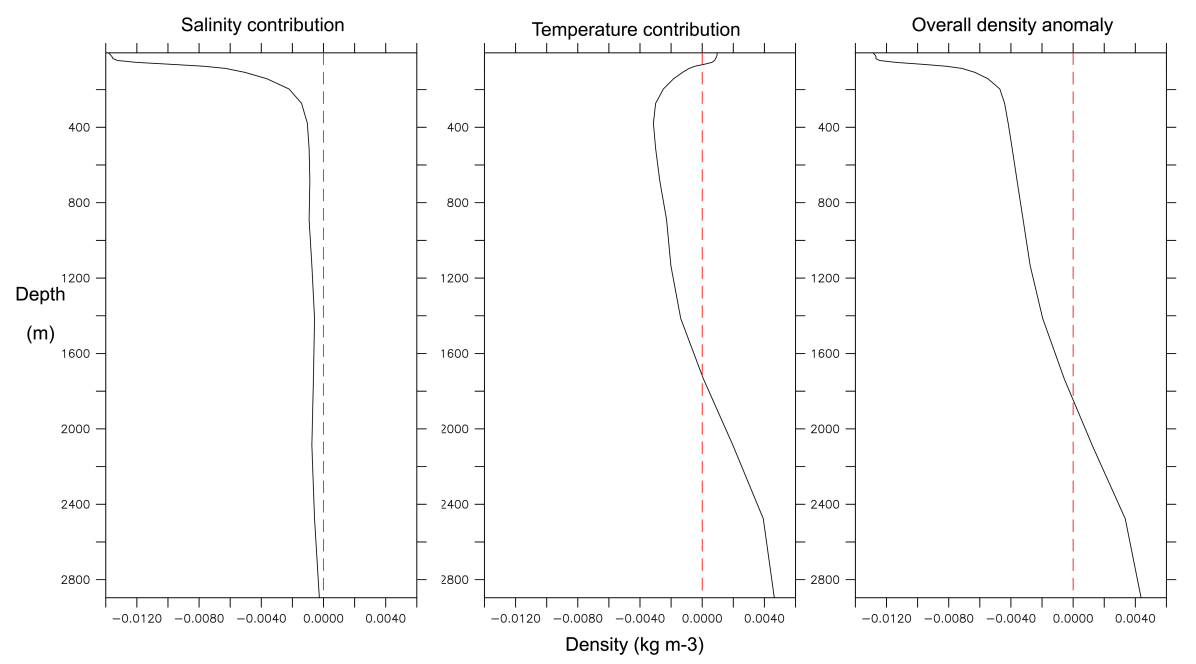

Figure S1: Unhosed stadial anomaly of the potential density profile in the subarctic North Atlantic (50N:70N). Left and middle panels show the salinity and temperature contributions to the subarctic $\mathrm{N}$ Atl. potential density anomaly of a weak AMOC state, relative to a strong AMOC state, as defined in Fig.3. Right panel shows the overall potential density anomaly. The accumulation of heat between $100 \mathrm{~m}-1800 \mathrm{~m}$ during a stadial partially counteracts the salinitydriven stabilization of the upper water column. Potential densities are calculated relative to the ocean surface. 

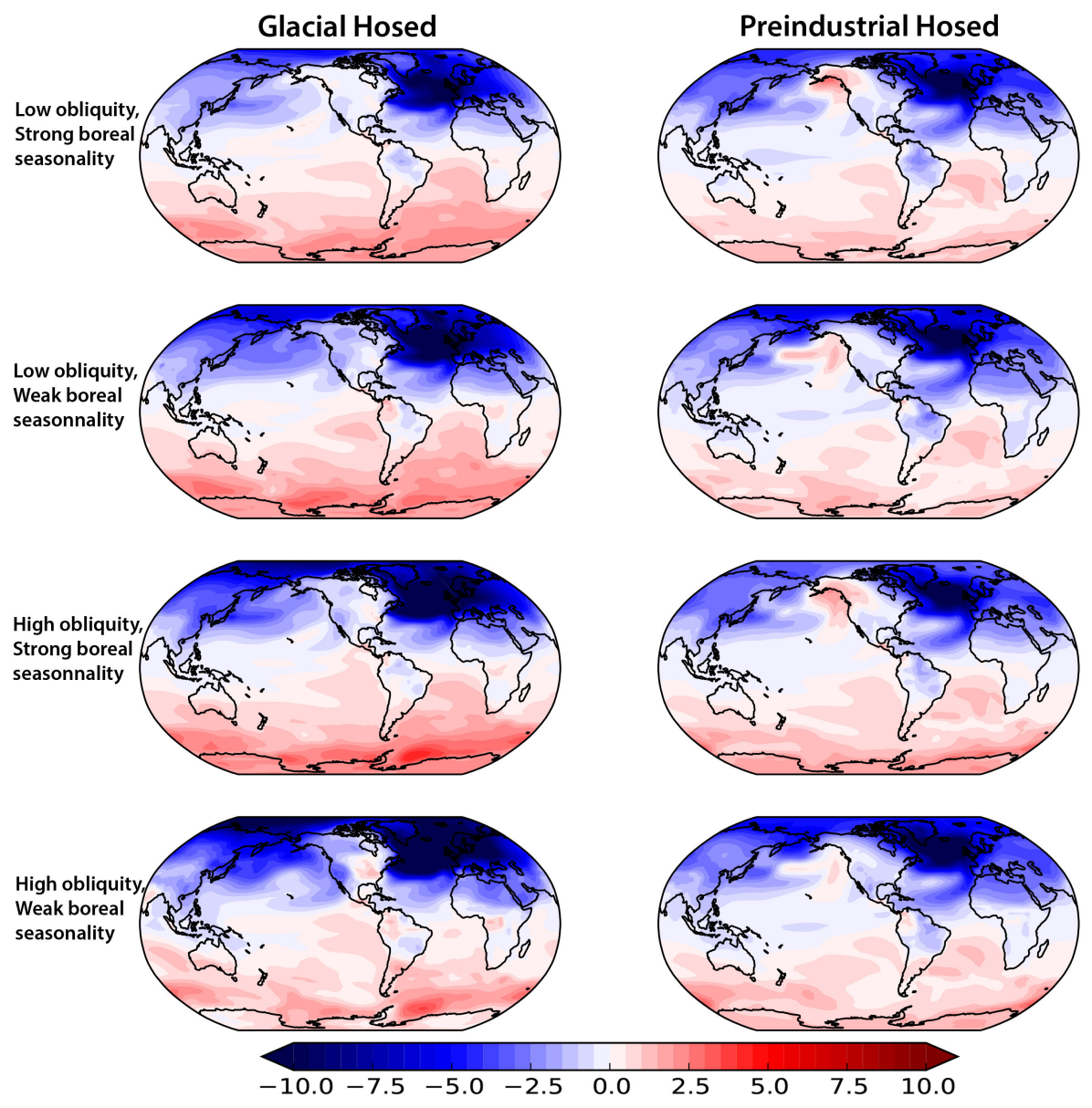

Figure S2: Stadial surface air temperature anomaly with weak and strong AMOC states as defined in figure 3 of the paper. Left column shows the glacial hosed simulations under the 4 orbital configurations individually. Right column shows the preindustrial hosed simulations under the 4 orbital configurations individually. Units in ${ }^{\circ} \mathrm{C}$. 

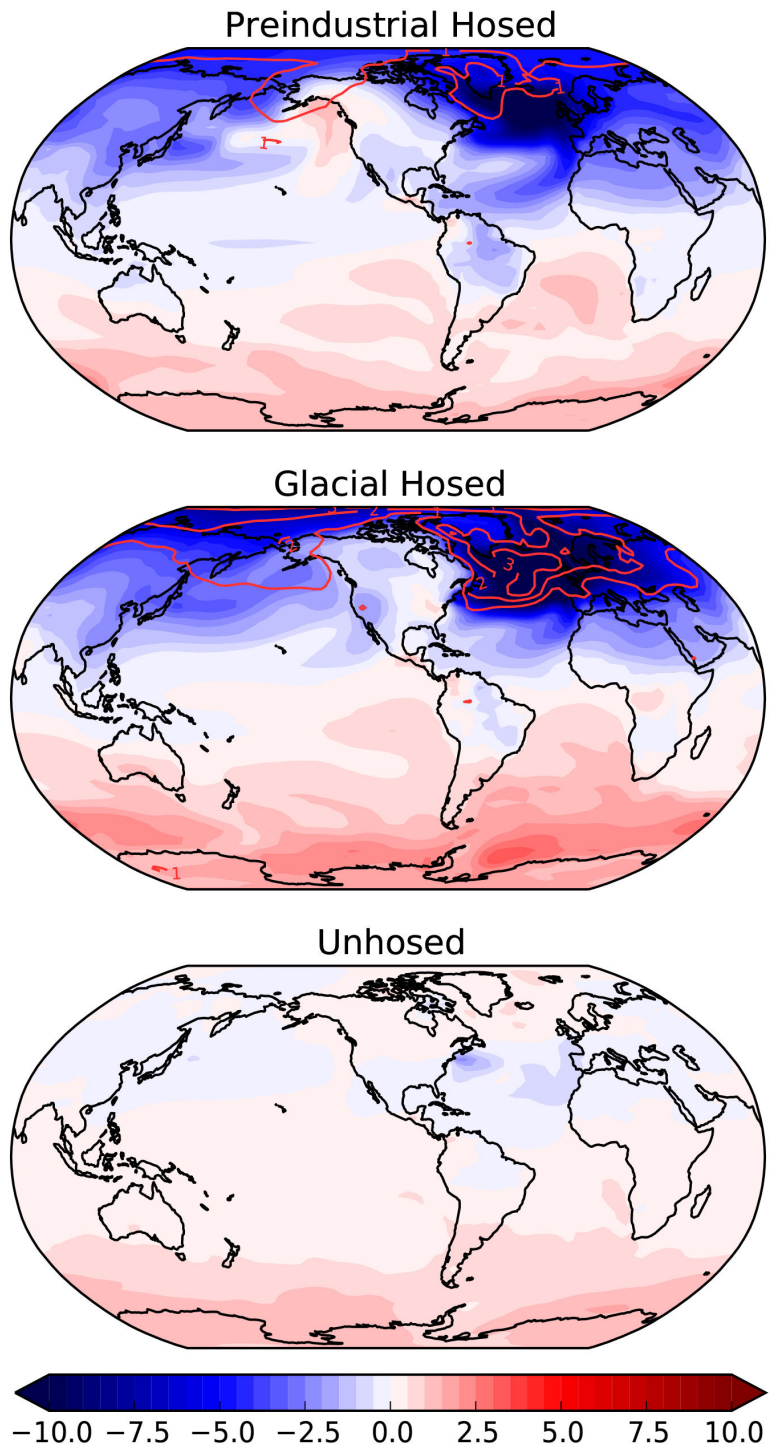

Figure S3: Alternate definition of the Unhosed stadial surface air temperature anomaly. The top two panels are the same as Figure 6, but the bottom panel differs in that the interval defined as the Unhosed interstadial is simulation years 8151-8250, 250 years later within the interstadial. Using the later interstadial time interval provides more time for the Southern Hemisphere temperature to increase, resulting in a magnitude of warming similar to that of the Preindustrial Hosed ensemble mean. By this time the temperature in the Northern Hemisphere has decreased almost to the stadial value. 

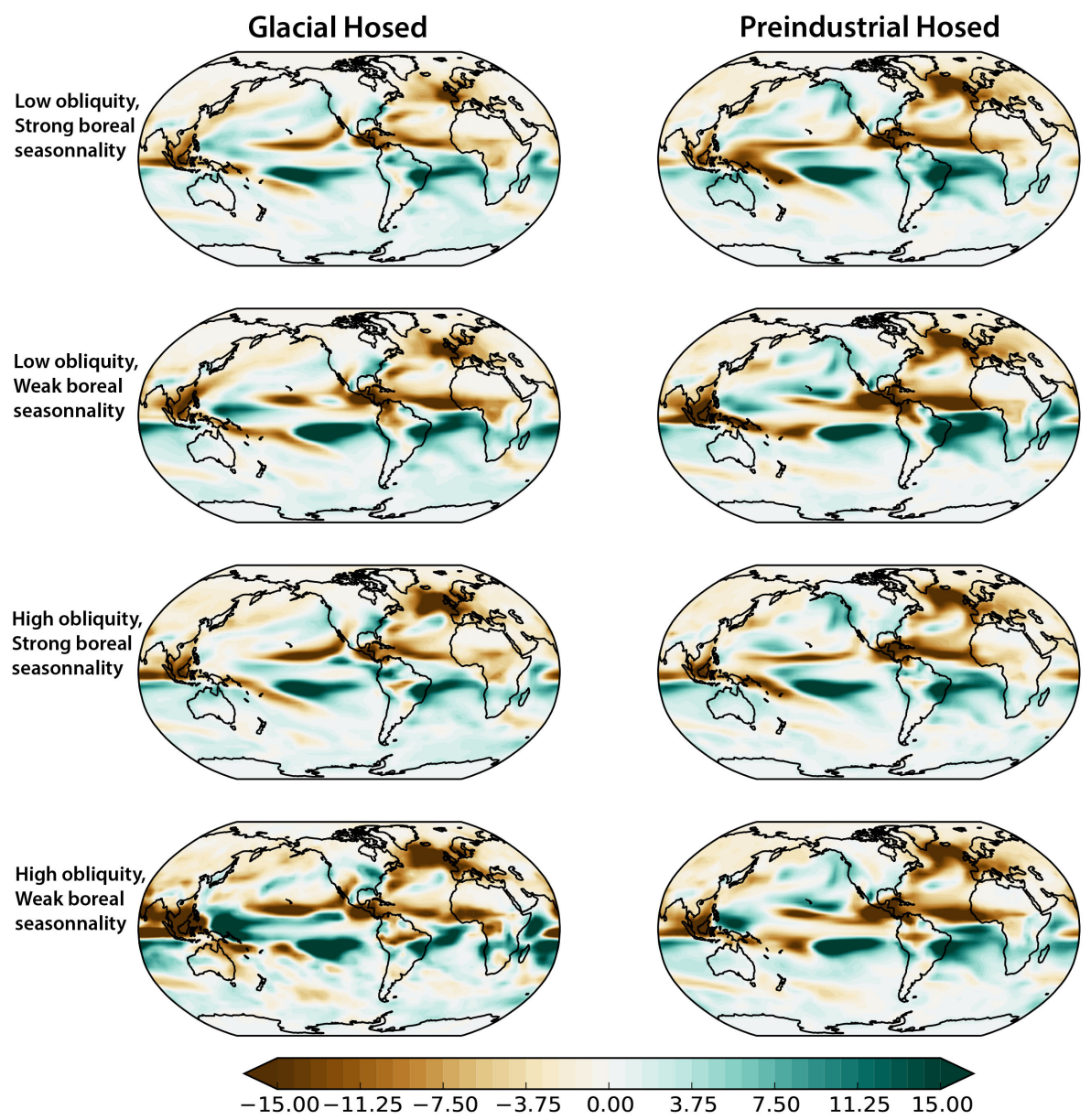

Figure S4: Stadial precipitation anomaly between weak and strong AMOC states as defined in figure 3 of the paper. Left column shows the glacial hosed simulations under the 4 orbital configurations individually. Right column shows the preindustrial hosed simulations under the 4 orbital configurations individually. Units in $10^{-6} \mathrm{~kg} \mathrm{~m}^{-2} \mathrm{~s}^{-1}$. 

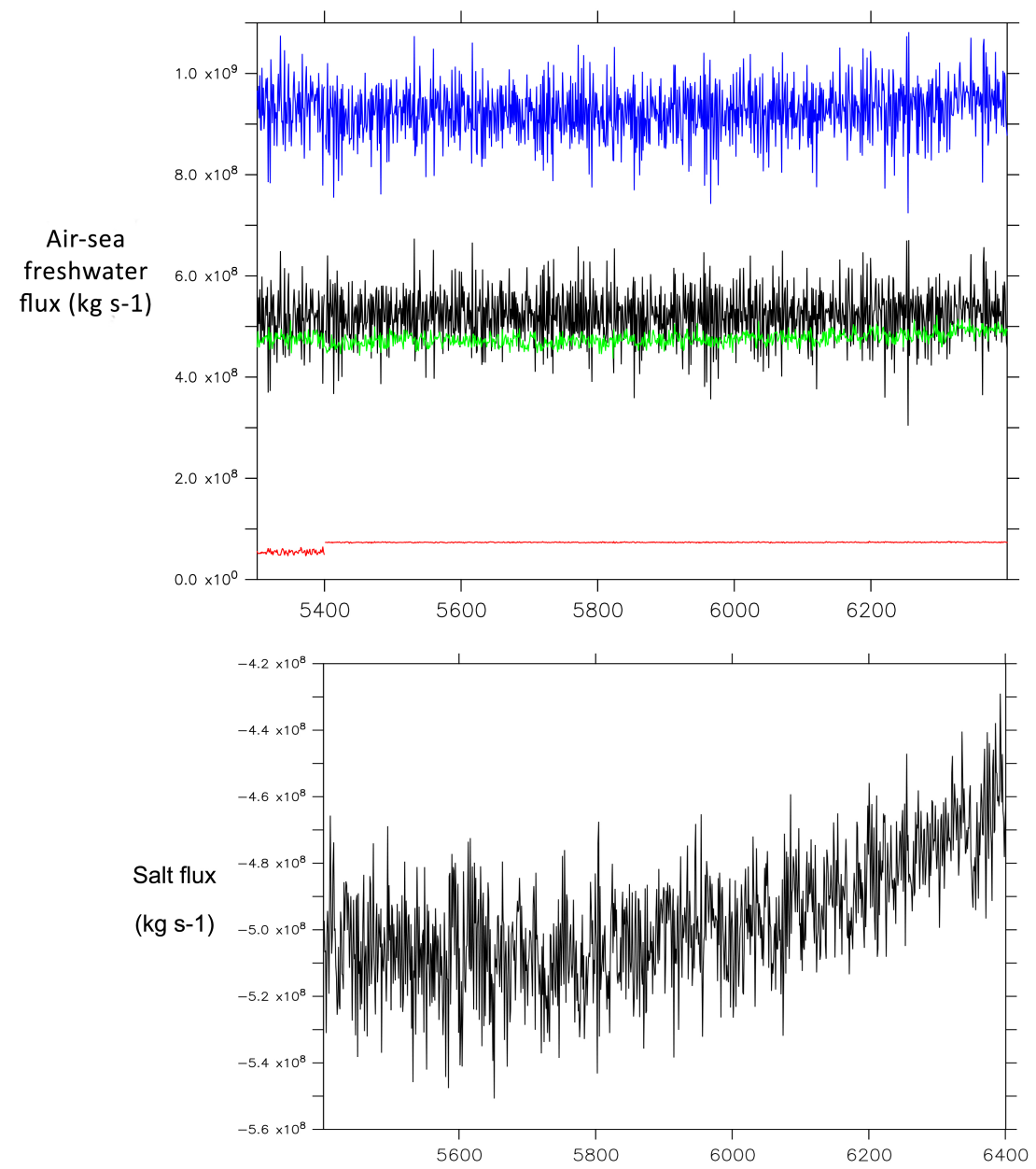

Figure S5: Southern ocean freshwater and salinity budgets for the HosedUnhosed simulation. Top panel: Air-sea flux of freshwater input to the Southern Ocean (50S to $80 \mathrm{~S}$ ) by precipitation and ice formation/melt (blue); removal of freshwater by evaporation (green); freshwater input by river runoff and ice calving (red); sum of the three air-sea freshwater terms as an input (black). Units in $\mathrm{kg}$ of freshwater $\mathrm{s}^{-1}$. The hosing starts at year 5401, which causes a slight increase in Antarctic ice calving due to the use of a preindustrial annual mean calving flux. Bottom panel: Changes in advective supply of freshwater to the Southern Ocean at intermediate depths, expressed as the northward salt advection at $50 \mathrm{~S}$ between 500 and $1500 \mathrm{~m}$ depth. Units in $\mathrm{kg}$ salt s $\mathrm{s}^{-1}$. The increase in northward salt advection (equivalent to an increase in southward freshwater advection) gradually increases in response to the freshwater-forced freshening of the North Atlantic, and occurs mostly within the Atlantic sector of the Southern Ocean (not shown). 

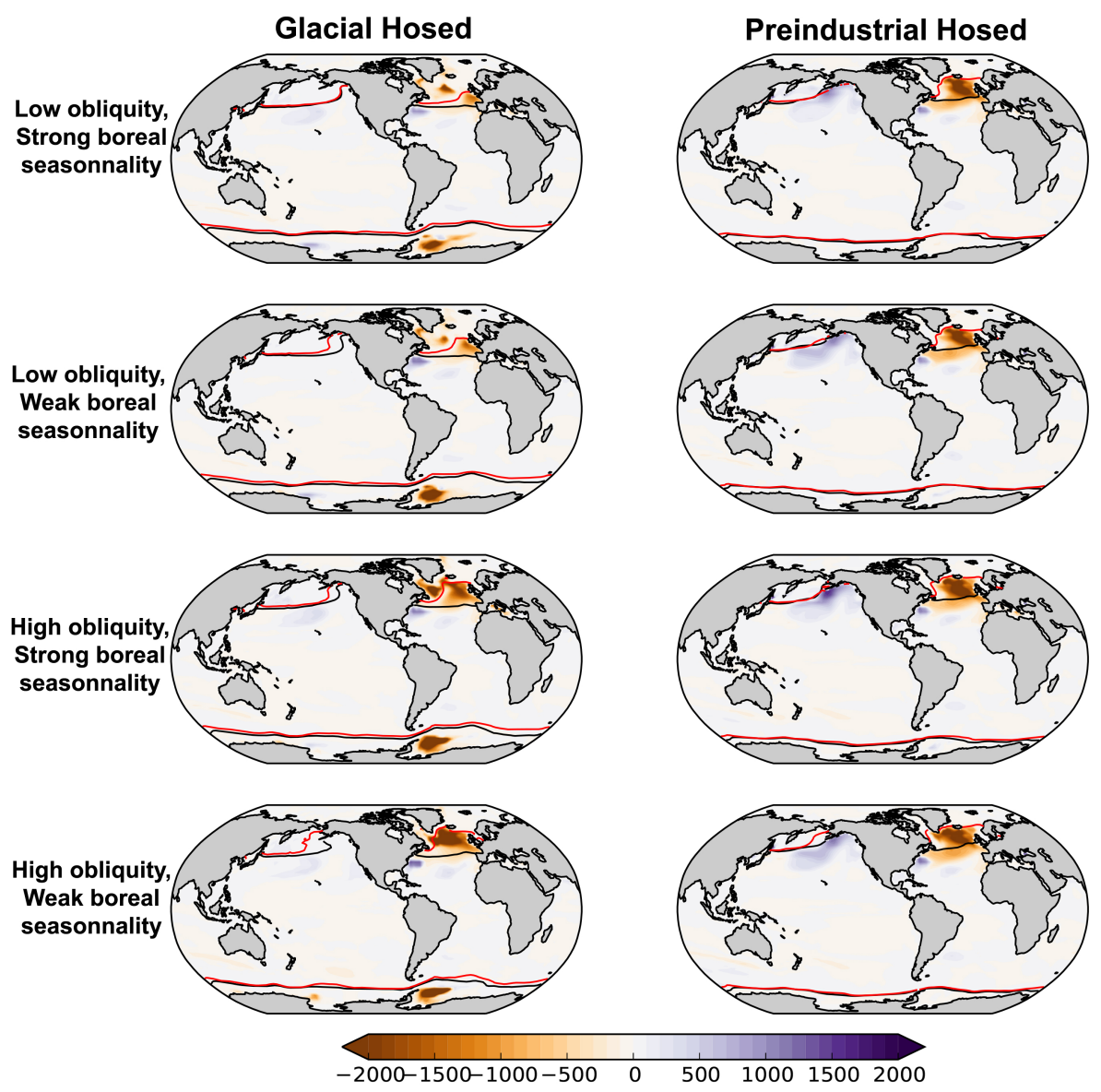

Figure S6: Stadial winter mixed-layer depth anomaly between weak and strong AMOC states as defined in figure 3 of the paper. Black and red contours show the sea-ice edge for the weak AMOC and strong AMOC states, respectively. Sea-ice edge is defined as $>30 \%$ of annually-averaged ice concentration. Left column shows the glacial hosed simulations under the 4 orbital configurations individually. Right column shows the preindustrial hosed simulations under the 4 orbital configurations individually. Shading units in $\mathrm{m}$. 

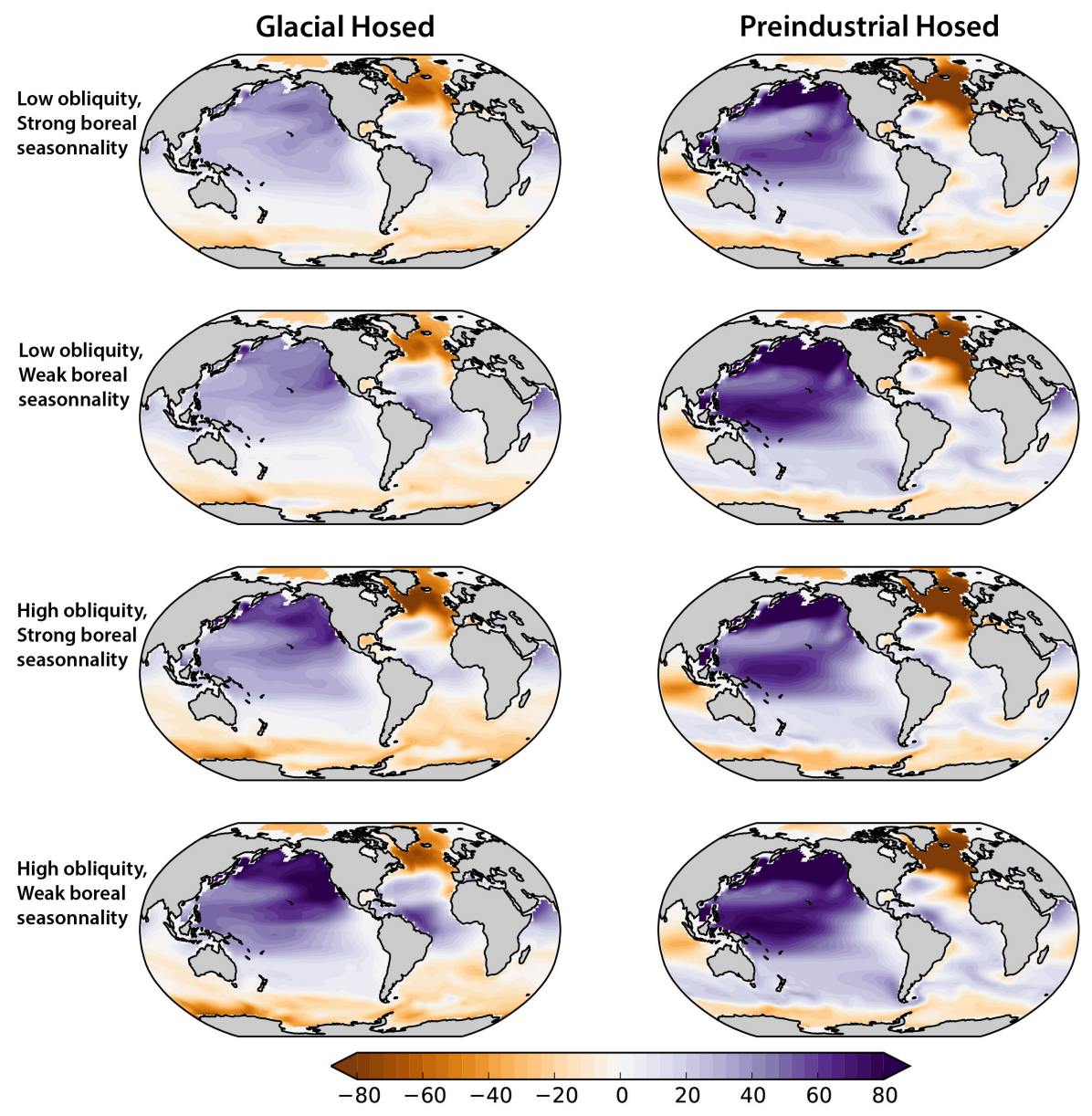

Figure S7: Stadial intermediate-depth (400m-1100m) oxygen concentration anomaly between weak and strong AMOC states as defined in figure 3 of the paper. Left column shows the glacial hosed simulations under the 4 orbital configurations individually. Right column shows the preindustrial hosed simulations

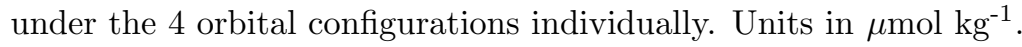



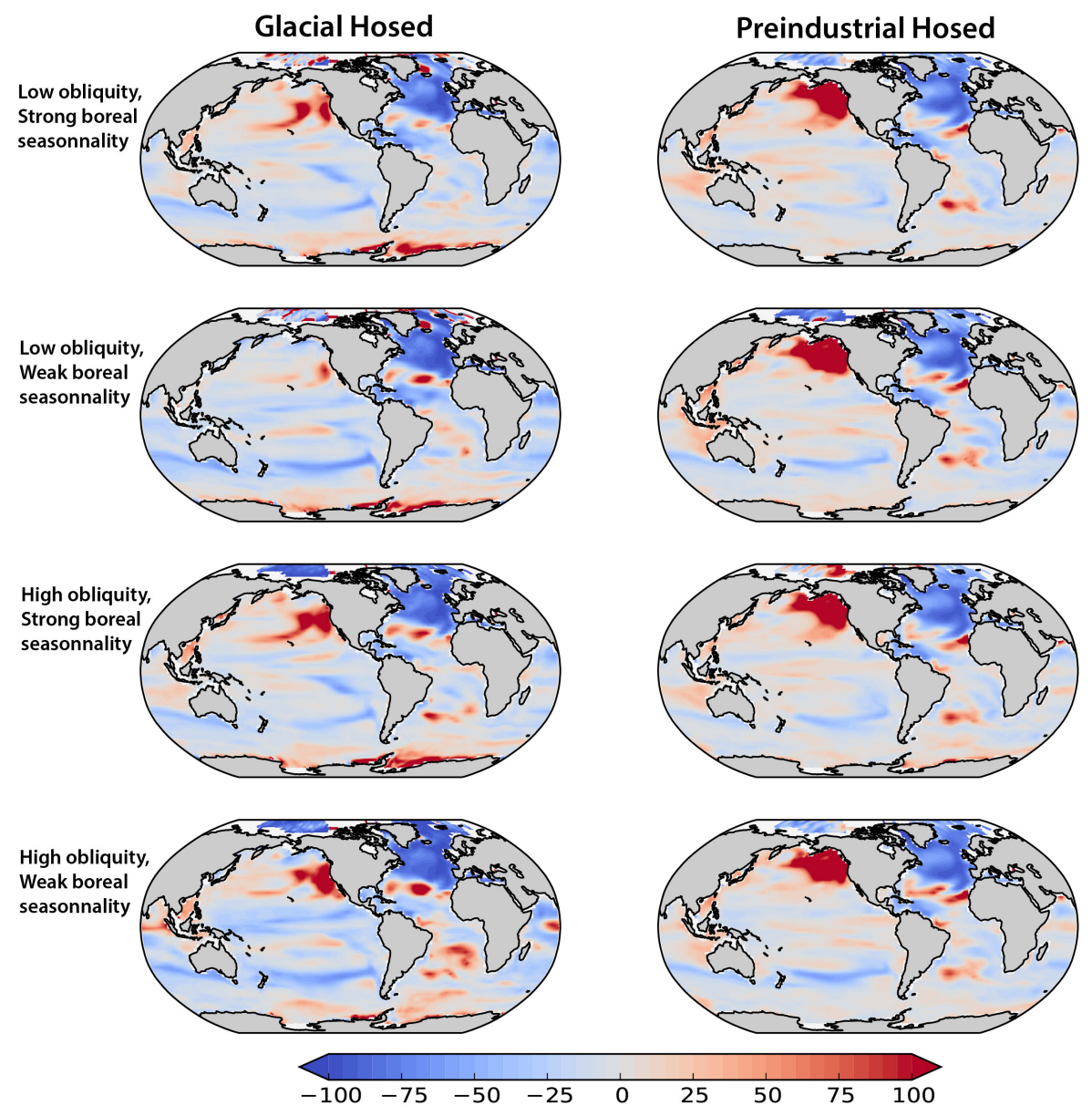

Figure S8: Stadial percent export production anomaly between weak and strong AMOC states as defined in figure 3 of the paper. Left column shows the glacial hosed simulations under the 4 orbital configurations individually. Right column shows the preindustrial hosed simulations under the 4 orbital configurations individually. Units in \%. 

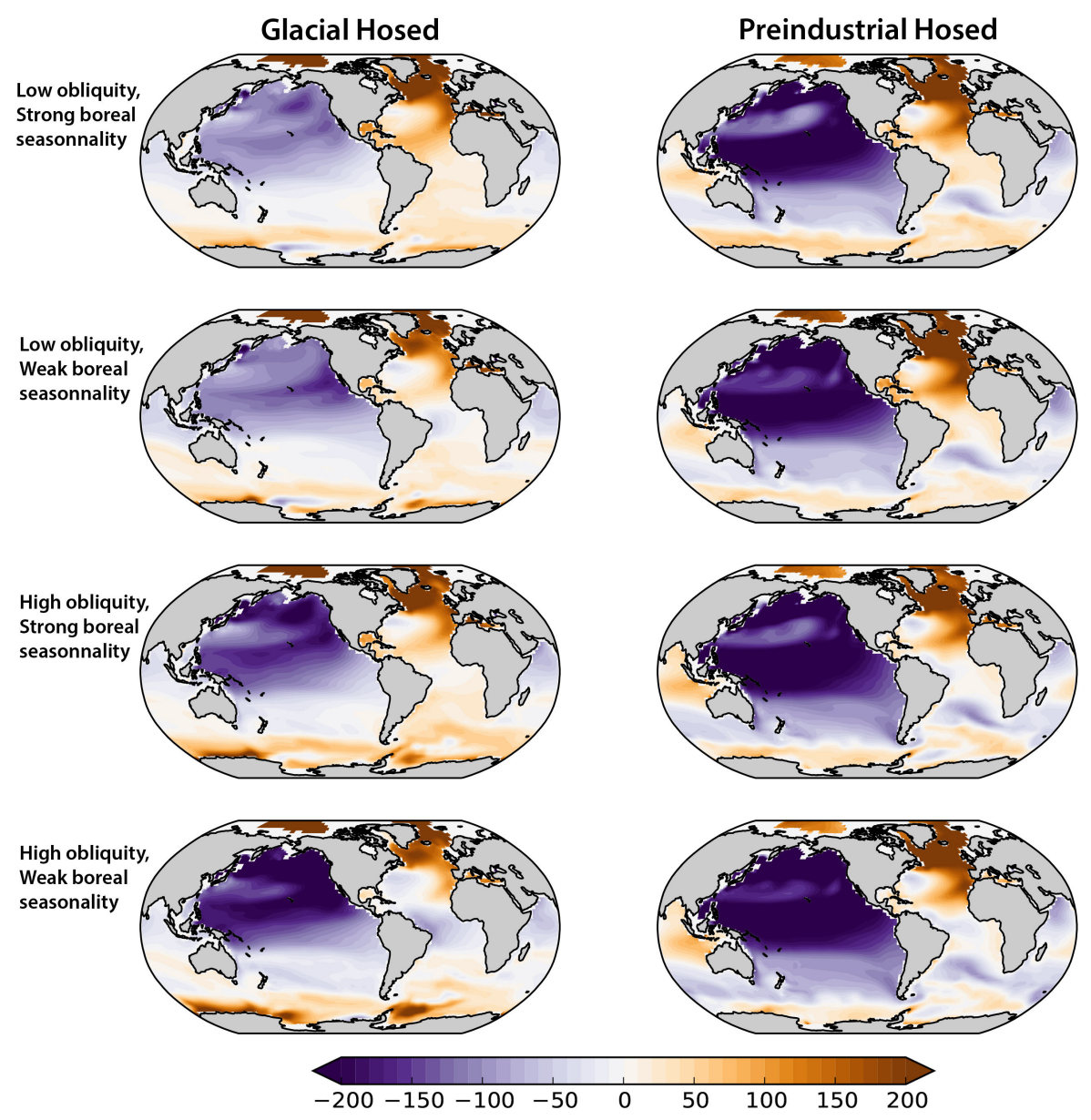

Figure S9: Stadial intermediate-depth (400m-1100m) age anomaly between weak and strong AMOC states as defined in figure 3 of the paper. Left column shows the glacial hosed simulations under the 4 orbital configurations individually. Right column shows the preindustrial hosed simulations under the 4 orbital configurations individually. Units in years. 